\title{
Synthetic Maxims of the Romantic Era in Goethe's Theoretical Search
}

\author{
Kozlova Tatiana \\ Russian State Specialized Arts Academy \\ Moscow, Russia \\ e-mail: Tatiana-koz@mail.ru
}

\begin{abstract}
The problem of synthesis as a principle of intersensitive associations is covered in the article: interaction of arts during Romanticism, Goethe's theoretical texts, his colour studies, arts articles, and where Goethe studies synthetic liaisons in works.
\end{abstract}

Keywords-synthesis; inter-sensitive associations; Romanticism; colour study; Goethe; harmonic system; synthetic liaisons

\section{Synthesis as an Aesthetic Problem}

In modern humanitarian science an approach to the study of synthetic phenomena has an inter-subject character. We can follow the synthesis of physiology, psychology, linguistics, poetics, music studies, art studies and aesthetics. In art theory and aesthetics, synthesis is called intersensitive psychical connections, including the results of its appearance in particular areas: in poetic texts of intersensitive content, in colour and animal images, inspired by music, in poetic and musical images inspired by art and artistic interaction.

For better understanding of synthesis a basic notion of "inter-sensitive connection", applied in art, according to B.M. Galeev, in interaction of sensitive reflection, appears on the principle of "similarity association". Synthesizes may be characterized as a "concentrated" and simulative actualization of the sensitive in the wide spectrum of its representations: first, it is a "multiplied" sensitivity and second, emotions, acting like a mediator of this multiplication. "Art in particular was the main sphere of social practice, where synthesis was cultured" [1].

Initially art had synthetic skills in its every kind. Thanks to synthesis the universality of the notion of general artistic space in art could be defined. Synthesis can be regarded as a form of general human sensitivity. The problem of education, sensation and co-sensation is a basic one when considering synthetic phenomena.

In art of the Romanticism epoch feelings, expression, and perception was accentuated. An issue of inter-sensual associations, connections between art and poetry, art and music, poetry and music, architecture and music were considered. Romantics thoroughly considered music and art relationships; their possible synthesis, connections between different spheres, provoked by different arts forms, and means the synthesis (although the term did not exist at that time).

When addressed to poetry, poets were made to find more definite words of synthetic content, artists had to find more adequate images and plots; connected with literature and to illustrate the notion of "musicality". Thus, in the Romanticism era the process of arts perception was connected with an idea of inter-sensitive association. Arts theoreticians, musicians and philosophers often offered synthetic analogies, for example, "architecture is a silent music" [2].

Sensitive-figurative reflection was also typical for Johann Goethe's works, where synthetic ideas sometimes appear: "Close your eyes, open your ears, from the easiest sound to the greatest harmony, from the most passionate cry to the shortest words of wisdom you will hear nature and only nature, which speaks to you, which reveals its essence, its power, its life and its relationship, that even a blind one, for whom this endless visible world is closed, may get the world of entire life" [3]. Here, essentially, synthesis is meant, which is represented by the author as the nature's activity. Indeed, human sensations and feelings, given by nature, obey the same organism, and the lacking feelings (sight, for instance) may be added by the hearing.

\section{Synthetic Principles in Goethe's "Teaching of COLOUR"}

A great interest is represented by the "Teaching of Colour", in which Goethe represented his vision of the following development of synthetic ideas. The colour, according to the author, affects sight and the soul. "This action can be specific, if it is taken apart, harmonic or not harmonic, often characteristic and if some colours are compared, always a definite one and important; it is connected to the sphere of the moral. That is why colour, taken as an element of art, can be used for the greater aesthetic aims [4]". Goethe indicates more than once to colour's ability to cause special spiritual conditions, which refers not only the colour itself, but also it's own perception.

Studying the colour theory, Goethe created his own system of colour harmony. His "Teaching of Colour" is a composition of the norm of the colour harmony, where every colour, having its temperament and combining differently with other colours, possesses an emotional 
energy. Emotional reactions to this relationship become an aesthetic basis of colour harmony.

Goethe used to talk about the existence of six major colours, creating three colour triangles. The first "characteristic combination" is yellow and blue, and is located horizontally, being the basis for the first colour triangle on the top of which is a purple colour. Over the yellow-blue combination the author positioned the second one - an orange-violet. Down from this basis the second colour triangle is located, on the top of which green colour is present.

For the first time Goethe made an attempt to make a hierarchy of the harmonious relationship in a six-colour circle, which represents three types of combination interactions - harmonic, characteristic, and not characteristic one. The emotional-figurative meaning of the harmonic combinations of colour - purple-green, violetyellow and orange-blue - is represented in the idea that contrast colours combine a whole; giving a sensation of peaceful completeness.

Goethe classified the colour types, specifying the three main ones: the powerful, the tender, and the bright - in which there is some domination. Active major red tones dominate the powerful, passive minor green-blue dominate the tender, and the bright combines the major and the minor circle combinations [5].

Although the use of the terms of "tone" and "shade" concerning art was not new, he suggested borrowing them from music to use in a different context. "We could compare a picture of a powerful effect to a major piece, and a canvas of a tender effect to a minor piece; even for the modifications of these two basic effects some other terms could be found [6]". Essentially, he spoke about not only the major and the minors of music structure, but about the effect caused by them. The same colorimetric of "powerful" or "tender" has a notion of sensation of its perception.

Similar comparisons are an attempt of synthetic decoration of thought, an attempt to compare the incomparable, which runs through Goethe's texts. Emotional effect comes first. The colour may bring joy or disturbance, anxiety, anguish or sorrow. Johann Wolfgang Goethe showed the presence of physiologic and psychological affect of the colour on a human being, connected to the human sensitivity.

Speaking about the theoretical music issues in a commentary to Didrot's texts, Goethe offers his own figurative sentensions (aphorisms), comparing rainbow to the musical sound [7]. Answering Diderot's words that "a rainbow for an artist is the same that basso generale means for music" [8], Goethe noted that applied to art, a rainbow may be considered the basis for harmony, which has to be taken into consideration when spreading the colours - but as a phenomenon of prism refraction the rainbow is just a private case of wider colour phenomena, which means that there is a higher general harmony, which laws obey all the others.
In comparison of rainbow to the basso generale in music Goethe does not agree with Diderot, offering music and theory arguments and marking that a rainbow is as little basso generale as a major accord is a general bass in music. But since there is a sound harmony, a major accord is harmonic. "If we continue our research, we'll also find a minor key, which by no means a major one, but is in all the circle of music harmony" [9]. As K. Kanisius believes, Goethe understands "harmony" in its original Greek sense of "harmotto" (to unite, to combine". Three sounds "in combination" with an accord (tone, the third stage and the quint) acquire here a harmonic combination.

K. Kanisius suggested that Goethe in this music theory appeared to be a Classicism philosopher, using the word of "harmony" according to Pythagorean school. He transfers this notion, coming from an antique music theory of harmony to art, when speaking about a higher general harmony. Goethe specifies the symbolic meaning of basso generale is in a scale of a professional artistic kind, noting that nobody could ruin or break the norms of basso generale without being it noticed by the experts and by the public, since ears will hear a break of harmony in music. Basso generale is associated with the harmonic mathematical rigidity.

There is no such a rigid theory in art like in music, concerning harmony rules. Diderot is speaking about the importance of anatomy depicting an appearance, discussing music comparisons. In his Diderot text remarks Goethe questioned what was external in organic nature, if it wasn't the interior part? External depiction and internal structure have the same relationship to each other - like in balance, so in movement. The equality of the interior and the exterior is a reason for comparison of art, music and poetry [10].

In his other article Goethe calls architecture a silent music and offers a figurative picture, connected to the idea of equality of the harmony of the beautiful sounds and city constructions, where "the spirit can not weaken, the energy can not sleep, an eye takes the function, the responsibility and a duty of the ear and on a common day citizens feel perfect..." In an opposite picture, where, in a poorly organized town "the sounds of bag-pipes, pipes and tambourines are heard the spectator should prepare to see bear's dances and monkey`s jumps" [11]. Here the synthetic connection between architecture and music is enriched by the word and visual picture. Co-feeling and co-sensation are considered, on which basis is the harmony of the sounds and words.

\section{SyNTHESIS IN RELATIONSHIP BETWEEN WORDS AND AN IMAGE}

At the end of the 18th century a problem of interaction between poetry and art was one of the central topics for aesthetic discussions. Goethe did not avoid figurative pictures. In his letters of the 1820-ies the poet made a formula: "a word and an image are correlative, looking for each other constantly" [12]. This topic was not only theoretical for Goethe, but also practical for his interpersonal associations: accompanying pictures and engravings with poetry (his own and other authors). In his 
drawing classes he saw some importance for poetic art, paying attention to the fact that exact and precise subject studying allows the making of an idea of sensitive subjects and nature contemplation, which may provide glorious feelings that can be turned into words [13]. Thus, poetry and art influence each other.

Gerhard Bauman noted that nature observation launched imagination, thinking, impressions, and projected situations with Goethe. From this perspective Goethe's drawings have a great meaning. They may be named "sketched ideas", or "an eye poetry", made with a stylus and a pencil in hand. Drawings and pictures inspired Goethe poetic imagination, where pictures of nature and imagination were the norm [14].

Poetry and art may approximate to each other without breaking each other's borders [15]. But, in some cases, a combination of these two kinds of art helps an artist to feel the artistic work more completely.

In an article dedicated to the German painter Wilhelm Tishbein (1751-1829), Goethe admired the artist's ability to animate the poetic world by the means of art, appraising highly this special quality, which did not allow the leaving of nature. His sketches to Wilhelm Tishbein's idylls are examples of pictures in imagination [16]. In poetry Goethe used the images, inspired by the works of art, natural phenomena, reality and vision. Descriptive poetic texts compliment a descriptive plot and move forward towards description of the characters with different kinds of music instruments. The text transfers visual sensation and also the general mood, inspired by music and dances. Following his descriptions and evaluating artistic motives, supplying them with poetic motives, Goethe concludes: "Everything that makes us happy with a movement - music, dance, except for something that comes from different life-moving elements, is divided by contrasts and joins harmonically again - all this is a reflection at a look on a picture, a beautiful symbol, allowing precise interpretations, leaving the image the same" [17]. At the same time he noted that he meant first of all his personal perception, since the image remained the same.

Another example is when Goethe accompanies paintings with poems. In his article "Art and the Antiquity" Goethe explained the appearance of a drawing, edited like engravings with poem dedication to the author's desire to approach the viewer or a reader to the drawer's state, when he was making sketches, noting that the author helps imagination to create visible images and sensations.

Under the synthesis of the experience of inter-sensitive associations Goethe turned more than once to his theory texts. Figurative thinking, turned to the sphere of the human sensitivity, symmetric connections and comparisons were found.

Thus we may conclude that, in spite of its distracted character, realization of synthetic problem in the Romanticism era prepared the ground for the synthetic actions in the art of the 20th century.

\section{REFERENCES}

[1] Galeev B.M. Aesthetic Synesthesis Problems. - Modern Laocon: Synesthesis: Problem in Aesthetics. - Moscow State University Publishers, 1992. P. 5-9.

[2] Goethe I.W. Teaching of Colour. Articles and Thoughts of Art. Moscow-Leningrad, 1936. P.355-356.

[3] Goethe I.W. Teaching of Colour.- Moscow, 2011. P. 3.

[4] Goethe I.W. Teaching of Colour. - Moscow, 2011. P. 40.

[5] Goethe I.W. The The Treatise of Colour. Selection Nature Studies Works. - Moscow, 1957. P. 356-357.

[6] Goethe I.W. The The Treatise of Colour. Selection Nature Studies Works. - Moscow, 1957. P. 356-357.

[7] Canisius Claus. Goethe und die Musik. - Munchen, 1998. P. 130.

[8] Canisius Claus. Goethe und die Musik. - Munchen, 1998. P. 141.

[9] Canisius Claus. Goethe und die Musik. - Munchen, 1998. P. 142.

[10] Canisius Claus. Goethe und die Musik. - Munchen, 1998. P. 130133.

[11] Goethe I.W. Teaching of Colour. Articles and Thoughts of Art. Moscow-Leningrad, 1936. P.355-356.

[12] Hecht Wolfgang. Goethe als Zeichner. - Leipzig, 1982. P. 11.

[13] Hecht Wolfgang. Goethe als Zeichner. - Leipzig, 1982. P. 9.

[14] Baumann Gerhart. Goethe: Schriften zur Kunst Vermitdungen einer Poetik / Goethe: Kunst und Wissenschaft. - Rombach, 1997. P. 9293.

[15] Baumann Gerhart. Goethe: Schriften zur Kunst Vermitdungen einer Poetik / Goethe: Kunst und Wissenschaft. — Rombach, 1997. P. 106108.

[16] Baumann Gerhart. Goethe: Schriften zur Kunst Vermitdungen einer Poetik / Goethe: Kunst und Wissenschaft. — Rombach, 1997. P. 112113.

[17] Goethe I.W. Teaching of Colour. Articles and Thoughts of Art. Moscow-Leningrad, 1936. P.290-291. 